\title{
EDUCAÇÃO FÍSICA NA EDUCAÇÃO INFANTIL: ESTRATÉGIAS METODOLÓGICAS PARA A QUALIDADE DA PRÁTICA PEDAGÓGICA
}

\author{
Leila Maira Borré ${ }^{1}$ \\ https://orcid.org/0000-0002-0861-1960 \\ Riller Silva Reverdito ${ }^{2}$ \\ https://orcid.org/0000-0003-0556-9151
}

RESUMO: o estudo é resultado de uma revisão sistemática que buscou identificar estratégias metodológicas que corroboram com a qualidade da prática pedagógica no ensino da Educação Física na Educação Infantil. As buscas foram realizadas em três bases de dados e cinco periódicos nacionais de divulgação dos conhecimentos específicos da Educação Física. Empregou-se a 'análise do conteúdo', no qual foram selecionados quatorze artigos classificados em A2, B1 e B2, com foco e escopo pautados nos aspectos pedagógicos do ensino da Educação Física. Foram analisados relatos de experiência, estudo de caso, estudos com o cotidiano e pesquisa-ação. Os dados encontram-se em seis categorias, sendo interdisciplinaridade, autonomia, relações interpessoais, diálogo, motivação e jogo simbólico. Conclui-se que o trabalho docente deve considerar a criança em sua totalidade, proporcionando atividades sistematizadas e contextualizadas que estimulem a autonomia, as relações com seus pares, a exploração e vivências de variadas práticas corporais nos diferentes tempos e espaços.

PALAVRAS-CHAVE: Educação Física, Educação Infantil, Práticas pedagógicas, Crianças.

\section{PHYSICAL EDUCATION IN CHILDREN EDUCATION: METHODOLOGICAL STRATEGIES FOR THE QUALITY OF PEDAGOGICAL PRACTICE}

ABSTRACT: the study results from a systematic review that sought to identify methodological strategies that corroborate with the quality of pedagogical practice on the teaching of Physical Education in Early Childhood Education. The searches were

\footnotetext{
${ }^{1}$ Mestre em Educação Física pela Universidade Federal de Mato Grosso (UFMT). Professora de Educação Física da Rede Estadual de Ensino (SEDUC). Cáceres - MT, Brasil. leilamayra@gmail.com

${ }^{2}$ Doutor em Educação Física pela Universidade Estadual de Campinas (UNICAMP). Professor Adjunto da Universidade do Estado de Mato Grosso (UNEMAT). Cáceres - MT, Brasil. Professor do Programa de Pós-graduação de Educação Física da Universidade Federal de Mato Grosso (PPGEF/UFMT). Cuiabá - MT, Brasil.rsreverdito@unemat.br.
}

Rev. Fac. Educ. (Univ. do Estado de Mato Grosso), Vol. 33, Ano 18, № 1, p. 95-118, jan./jul., 2020 (Epub Ahead of Print 15 set., 2019 ). 
conducted in three databases and five national journals to disseminate the specific knowledge of Physical Education. The analysis was based on the 'content analysis', selecting fourteen articles classified as A2, B1 and B2, with focus and scope based on the pedagogical aspects of Physical Education teaching. We analyzed reports of experience, case study, studies with daily life and action-research. The data involves six categories: interdisciplinarity, autonomy, interpersonal relations, dialogue, motivation and symbolic play. It is concluded that the teaching work should consider the child in its totality, providing systematized and contextualized activities that stimulate autonomy, the relations with its pairs, exploration and experiences of various corporal practices in different times and spaces.

KEYWORDS: Physical Education, Early Childhood Education, Pedagogical Practices, Children.

\section{EDUCACIÓN FÍSICA EN LA EDUCACIÓN INFANTIL: ESTRATEGIAS METODOLÓGICAS PARA LA CALIDAD DE LA PRÁCTICA PEDAGÓGICA}

RESUMEN: el estudio es el resultado de una revisión sistemática que busca identificar estrategias metodológicas que corroboran con la cualidad de la práctica pedagógica en la enseñanza de la Educación Infantil. Las búsquedas se realizaron en tres bases de datos y cinco revistas nacionales para la difusión de conocimientos específicos sobre Educación Física. Se utilizó un análisis de contenido, en el que se seleccionaran catorce artículos clasificados en A2, B1 y B2, con enfoque y alcance basados en los aspectos pedagógicos de la enseñanza de Educación Física. Fueran analizados los informes de la experiencia, estudio de caso, los estudios con el cotidiano y en pesquisa de acción. Los datos encuentra en seis categorías, siendo interdisciplinaridad, autonomía, relaciones interpersonales, diálogo, motivación y juego simbólico. Concluye que en el trabajo del profesor debe considerar el niño en su totalidad, proporcionando actividades sistematizadas y contextualizada que estimulen la autonomía, las relaciones con sus parejas, la exploración y experiencia de las variadas prácticas corporales en los diferentes tempos y espacios.

PALABRAS CLAVE: Educación Física, Educación Infantil, Prácticas pedagógicas, Niños.

\section{Introdução}

As discussões que incluem o educar na proposta pedagógica da Educação Infantil tornaram-se evidentes a partir de 1998, com a criação do Referencial Curricular Nacional para a Educação Infantil - RCNEI, transfor- 
mando-se no principal instrumento norteador dos objetivos, conteúdos e orientações didáticas para o atendimento de crianças de zero a seis anos ${ }^{3}$. Dessa maneira, as instituições de Educação Infantil além do cuidar, passaram a exercer a função de educar.

No que se refere à Educação Física, tornou-se componente curricular a partir da Lei de Diretrizes e Bases da Educação Nacional (LDB) de 1996, contudo as discussões ampliam-se com a aprovação da Lei $n^{\circ} 10.328$ de dezembro de 2001, que inclui o termo 'obrigatório', retificando as condições que geravam dúvidas sobre a obrigatoriedade da Educação Física em todas as etapas de ensino.

Na Educação Infantil, a Educação Física é um tempo didático de sistematização dos conhecimentos acerca da cultura corporal de movimento, de modo que o movimento torna-se imprescindível no processo de aprendizagem da criança (OLIVEIRA; MARTINS; PIMENTEL, 2013). A Educação Física adquire legitimidade quando o/a professor/a, ao desenvolver suas práticas pedagógicas reconhece a criança como coautora de sua aprendizagem. As práticas pedagógicas envolvem o planejamento, metodologia e avaliação do processo de aprendizagem (ZABALA, 1998), independentemente do nível em que o/a professor/a atua. Contudo, de imediato, podemos afirmar que a qualidade da prática pedagógica surge da relação entre o pedagógico e o didático, ou seja, da relação existente entre a teoria e a prática, que resulta na compreensão do professor/a sobre os objetivos, necessidades da criança e do contexto em que está inserida.

Apesar de a Educação Física ser componente curricular obrigatório da educação básica, identifica-se uma linha tênue na Educação Infantil, pois não há menção desta enquanto disciplina. Não se trata em fomentar as discussões acerca das aulas serem ministradas ou não por especialista, mas de circunscrever os aspectos metodológicos que caracterizam a qualidade das práticas pedagógicas com os conteúdos da Educação Física na Educação Infantil. Entendemos que ainda há um longo caminho a ser percorrido, visto o número restrito de instituições de Educação Infantil em que o/a professor/a de Educação Física está inserido, além da dificuldade em conciliar as rotinas das instituições com as práticas corporais, como também a necessidade de significação da Educação Física enquanto espaço e tempo de aprendizagem, e não apenas como momento recreativo ou de relaxamento corporal. Assim, as

${ }^{3}$ Conforme redação dada pela Lei no 12.796, de 2013 que altera a Lei no 9.394, de 20 de dezembro de 1996, a Educação Infantil, primeira etapa da educação básica, tem como finalidade o desenvolvimento integral da criança de até 5 (cinco) anos.

Rev. Fac. Educ. (Univ. do Estado de Mato Grosso), Vol. 33, Ano 18, № 1, p. 95-118, jan./jul., 2020 (Epub Ahead of Print 15 set., 2019 ). 
práticas pedagógicas voltadas para esta área de conhecimento não podem ser resumidas em momentos de parquinho ou na aplicação de inúmeros jogos e brincadeiras sem finalidade ou, quem dera, com uma sequência didático-metodológica. No entanto, apesar de reconhecida a complexidade do processo de ensino e aprendizagem na Educação Infantil, a prática pedagógica no ensino da Educação Física tem sido negligenciada (FALKENBACH; DREXLER; WERLE, 2006; UCHÔA; PRODÓCIMO, 2008; TOLOCKA et al., 2009; FARIA et al., 2009; RICHTER; VAZ, 2010; ANDRADE FILHO, 2013; SURDI; MELO; KUNZ, 2016).

Moura, Nunes Costa e Antunes (2016) reiteram que, se por um lado, muitos estudos dedicam-se em possibilitar discussões em busca da legitimação Educação Física no currículo da Educação Infantil (SAYÃO, 1999; AYOUB, 2001; BASEI, 2008; CAVALARO; MULLER, 2009), por outro, ainda são poucos os que dedicam atenção à qualidade da prática pedagógica quando se trata do desenvolvimento dos conteúdos da Educação Física. Diante do exposto, quais estratégias metodológicas corroboram com a qualidade da prática pedagógica da Educação Física na Educação Infantil? Assim sendo, buscamos subsídios que orientem o trabalho pedagógico dos professores nesta etapa de ensino. Longe de apresentar um modelo engendrado, espera-se que o estudo contribua para a reflexão e auxílio aos professores que atuam com a Educação Física na Educação Infantil.

\section{A Educação Física na Educação Infantil}

Diversos são os embates para a legitimação da Educação Física na educação brasileira e com a Educação Infantil não poderia ser diferente. A Educação Física tornou-se componente curricular obrigatório na Educação Infantil, no entanto, por não ter seu currículo organizado de maneira disciplinar, emergem dúvidas quanto ao lugar e espaço que ela ocupa nessa etapa de ensino (RICHTER; VAZ, 2010). Contudo, sabemos da importância dos conteúdos da cultura corporal de movimento para o desenvolvimento da criança, e que o brincar é um dos principais direitos de aprendizagem na Educação Infantil. Nesse sentido, Sayão (1999) e Ayoub (2001) reforçam a ideia de não pensar em professoras/es 'generalistas' ou 'especialistas', mas em professoras/es de Educação Infantil, compartilhando diferentes saberes para construção de projetos educativos, considerando e valorizando os interesses das crianças.

Conforme as Diretrizes Curriculares Nacionais para a Educação Infantil (DCNEI) (BRASIL, 2010), a Educação Infantil é componente da Educação Básica e caracteriza-se por espaços institucionais que educam e cuidam de crianças de 
0 a 5 anos de idade, respeitando seus princípios éticos, estéticos e políticos. A proposta pedagógica deve fundamentar-se nas interações e brincadeiras como eixos norteadores, sendo asseguradas as crianças seis direitos de aprendizagem: conviver, brincar, participar, explorar, expressar e conhecer-se (BRASIL, 2017). Para que tais direitos de aprendizagem sejam alcançados é necessário o desenvolvimento de um trabalho pedagógico que não priorize apenas os cuidados básicos requeridos, mas que também contemple as intencionalidades educativas desta etapa de ensino.

Ao professor/a compete a seleção dos conteúdos, o planejamento, a mediação e avaliação do processo de aprendizagem. Por conseguinte, é imprescindível que o/a professor/a exerça sua função de mediador/a, ao possibilitar situações coletivas de aprendizagem, sem deixar de considerar as características individuais de cada criança, tornando-as protagonistas de sua aprendizagem (AYOUB, 2005; FREIRE; SANTANA, 2010; SANTOS; LIMA, 2009; MACHADO; FAGUNDES; SILVA, 2011), a fim de alcançar os objetivos de aprendizagem dos diversos campos de experiência. Conforme a Base Nacional Comum Curricular (BNCC), os campos de experiências compreendem a organização curricular, contemplando experiências, saberes e situações concretas do cotidiano da criança (BRASIL, 2017). A Educação Física - enquanto componente curricular - deve agregar e viabilizar em sua proposta pedagógica os conhecimentos advindos dos campos de experiências propostos pela BNCC, reconhecendo as crianças como autoras e protagonistas no processo de aprendizagem.

A prática pedagógica deve envolver situações em que a criança possa interagir com seus pares e com adultos, participando das relações sociais, ampliando o modo de perceber, valorizar e respeitar a si mesma e os outros. Deve tornar-se progressivamente consciente de sua corporalidade (BRASIL, 2017), explorando as diferentes linguagens e movimentos, como também se comunicando e expressando-se a partir do entrelaçamento entre o corpo, emoção e linguagem (MATURANA; VERDEN-ZÖLLER, 2004). É o momento em que deve ocorrer a emancipação e liberdade, sendo o movimento corporal o principal meio de experimentação e vivência das práticas propostas (TOLOCKA et al., 2009; FARIA et al., 2009; MOURA; NUNES COSTA; ANTUNES, 2016; SURDI; MELO; KUNZ, 2016; BRASIL, 2017). As brincadeiras devem permear situações em que a criança seja capaz de observar, explorar, manipular e ressignificar objetos, criando novas situações, solucionando problemas e situando-se no tempo e no espaço, convivendo com diferentes manifestações da cultura, dentre elas, as danças, mímicas, encenações e as diferentes formas de expressão (BRASIL, 2017). 
Os documentos normativos e orientadores, apesar de nortearem os currículos, e proporem elementos necessários para o desenvolvimento da criança, não garantem a efetivação de práticas pedagógicas que vão ao encontro com o proposto. Os estudos de Falkenbach, Drexler, Werle (2006), Uchôa e Prodócimo (2008), Tolocka et al. (2009), Faria et al. (2009), Richter e Vaz (2010), Andrade Filho (2013) e Surdi, Melo e Kunz (2016), demonstram que as aulas no ensino infantil apresentam práticas pedagógicas errôneas, que acabam limitando as diferentes formas de movimento como também a capacidade criativa da criança.

Falkenbach, Drexler, Werle (2006), ao analisarem a compreensão das professoras sobre a Educação Física na Educação Infantil, identificaram que a Educação Física não é pedagogicamente reconhecida. Os autores destacam algumas fragilidades como a separação de meninos e meninas durante as atividades, pouca interação entre professoras e crianças, e aulas restritas a momentos de recreação com limitadas experimentações corporais. No discurso das professoras, o brincar somente é valorizado "enquanto estiver a serviço de uma aprendizagem (valores, leitura, escrita, cálculo), o brincar como forma de exteriorização e de conhecimento da criança não é reconhecido" (FALKENBACH; DREXLER; WERLE, 2006, p. 100).

Em sua análise, Uchôa e Prodócimo (2008) identificaram que a brincadeira é utilizada como uma maneira de controlar as crianças, sendo empregadas, como forma de gratificação às crianças que finalizassem as atividades escritas e como punição e ameaça aos que resistiam às normas impostas pelo professor. Surdi, Melo e Kunz (2016) investigaram o brincar e o se movimentar no contexto infantil e identificaram que essas práticas, muitas vezes, acontecem com intuito de competição e obtenção de um resultado final, priorizando os movimentos que aconteciam apenas em seu caráter funcional e utilitário, controlados pelo professor.

No que concerne à restrição do movimento, Andrade Filho (2013) corrobora este entendimento ao considerar que a cultura institucional acaba por sistematizar o movimento em detrimento da ordem. Enfatiza ainda, as dificuldades das/os professoras/es organizarem pedagogicamente aulas que envolvam o movimento corporal, com atividades, em sua maioria, impostas e engessadas. Richter e Vaz (2010, p. 66) salientam que as práticas pedagógicas que incidem sobre o corpo da criança estão demarcadas "por processos de ajustamento, modelagem, regulação e disciplinamento". Além da negação do corpo e o seu intenso controle sobre o espaço, Uchôa e Prodócimo (2008), Tolocka et al. (2009) e Faria et al. (2009) salientam que os horários e rotinas das 
instituições limitam o tempo destinado para as brincadeiras, não privilegiando momentos de interação com crianças de outras idades.

Considerando tais aspectos, Ayoub (2001) ressalta que a ação do/a professor/a não deve presidir a de mero aplicador/a de infinitos 'joguinhos' com a função de divertir as crianças, como se necessitassem de intervenção pedagógica. Ao contrário, é na brincadeira e nas dimensões lúdicas que o/a professor/a deve mediar e sistematizar intencionalmente as atividades, a fim de atingir os objetivos elencados em seu planejamento. No que se refere ao planejamento, Ferraz e Macedo (2001) salientam a necessidade de o/a professor/a conhecer o que está sendo desenvolvido pelas demais áreas do conhecimento, preservando a especificidade dos conteúdos da Educação Física e, ao mesmo tempo, interagindo com a totalidade do projeto pedagógico da escola, por conseguinte, interdisciplinar.

A interdisciplinaridade escolar, proposta por Fazenda (2008, p. 21), possui, como principal característica, a ação educativa, configurando-se pelas "noções, finalidades, habilidades e técnicas visam favorecer, sobretudo o processo de aprendizagem, respeitando os saberes dos alunos e sua integração". Como estratégia de articulação da Educação Física, Richter e Vaz (2012) apontam os projetos coletivos como principal meio de superar a demarcação rígida de espaços e horários, propiciando a participação de diferentes profissionais que atuam neste contexto, como também, a integração entre crianças de diferentes faixas etárias.

Falkenbch, Drexsler e Werle (2006) ressaltam que a Educação Física precisa conquistar o seu espaço como uma prática de valor pedagógico, proporcionando às crianças diferentes formas de sentir, pensar, problematizar e recriar os movimentos, com o propósito de superar as nuances do controle do corpo nos espaços, tornando o movimentar-se a expressão central da criança, desmistificando a concepção enraizada de que o movimento é sinônimo de desordem e bagunça (UCHÔA; PRODÓCIMO, 2008). Assim, conforme Richter e Vaz (2012), o/a professor/a não deve exigir a repetição de gestos estereotipados, mas explorar as diversas práticas corporais, possibilitando o acesso aos jogos, brincadeiras, cantigas de roda e danças, a fim de proporcionar-lhes conhecimento sobre o corpo, como também a interação e socialização com seus pares.

O papel do/a professor/a vai além da mera reprodução e aplicação de atividades descontextualizadas. As suas ações precisam transformar-se em reflexão do fazer pedagógico, repensando, reconstruindo e reinventando sua própria prática (CAPARROZ; BRACTH, 2007; RICHTER; VAZ, 2012), atendendo 
as especificidades do contexto ao qual a instituição está inserida e as particularidades de cada criança. Em decorrência destas afirmações, além de direcionar o processo educativo e identificar os progressos e dificuldades da criança, a avaliação tem como finalidade proporcionar ao professor/a tais reflexões (HOFFMANN, 2012). Assim, no que se refere à Educação Física, a avaliação deve utilizar diversos instrumentos (observações, relatórios, portfólios), respeitando as fases de desenvolvimento de cada criança, estando estreitamente articulada com os objetivos de aprendizagem na Educação Infantil.

Diante do exposto, é inaceitável pensar na significação da Educação Física na Educação Infantil, sem se pensar e discutir a qualidade da prática pedagógica do/a professor/a. Nesse sentido, qualidade supõe uma intencionalidade educativa durante a sistematização dos conteúdos (UCHÔA; PRODÓCIMO, 2008); uma ação participativa em que professor e alunos atuam de forma indissociável como autores do processo de aprendizagem interagindo com o contexto cultural (MELLO, 2014) e um processo avaliativo que estimule e valorize a criança (HOFFMANN, 2012).

Logo, o objetivo do estudo é identificar estratégias metodológicas que corroboram com a qualidade da prática pedagógica no ensino da Educação Física na Educação Infantil. Visto que as práticas pedagógicas "não admitem receitas universalmente válidas a serem aplicadas sobre as crianças", mas exigem constante problematização e reflexão (RICHTER; VAZ, 2012, p. 323) e que "nem tudo se aprende do mesmo modo, no mesmo tempo nem com o mesmo trabalho", questionando-nos acerca da existência ou não de uma melhor maneira de ensinar (ZABALA, 1998, p. 86). Em vista destes aspectos, elencaremos elementos metodológicos que podem contribuir para a prática pedagógica relacionada ao ensino dos conteúdos da Educação Física na Educação Infantil.

\section{Procedimentos Metodológicos}

Trata-se de um estudo de revisão sistemática (THOMAS; NELSON; SILVERMAN, 2012; GOMES; CAMINHA, 2014). Para o estudo, foi realizado um levantamento inicial em cinco periódicos nacionais voltados para a divulgação dos conhecimentos específicos na área da Educação Física: Revista de Educação Física (UEM), Motrivivência (UFSC), Motriz (UNESP), Movimento (UFRGS) e Pensar a Prática (UFG). Para a escolha dos periódicos, elegeram-se os nacionais por apresentarem artigos primários condizentes com a realidade de nosso 
país, utilizando como critério a Qualis (classificação de periódico 2015) disponibilizada pela Plataforma Sucupira, classificados em A2, B1 e B2, com foco e escopo pautados nos aspectos pedagógicos do ensino da Educação Física. Não havendo um número significativo de estudos, as buscas ampliaram-se, sendo realizadas, ainda, em três bases de dados (Scielo, LILACS e Google Acadêmico), escolhidas por duas características: a) o livre acesso nas buscas dos periódicos disponibilizados; b) relevância que possuem na difusão do conhecimento científico na área da Educação Física e Educação.

As buscas foram realizadas entre os meses de janeiro e fevereiro do ano de 2017, no intuito de localizar artigos publicados entre 1990 e 2016 . Foram utilizados os termos-chave 'Educação Física' e 'Educação Infantil', empregando 'and' como operador nas buscas, ou seja, ambos os termos deveriam constar em todas as categorias. Em seguida foi realizada a leitura inicial dos títulos e resumos com a finalidade de decidir sobre o enquadramento do artigo em relação ao objeto de estudo: práticas pedagógicas e os conteúdos da Educação Física na Educação Infantil. Optamos por enfatizar, em nossa análise de dados, estudos pautados de pesquisa de campo, sendo do tipo relatos de experiência, estudo de caso, estudo com o cotidiano e pesquisa-ação, por entender a necessidade de estabelecer relações reciprocas entre ação, pesquisa e reflexão (FREIRE; SANTANA, 2007).

\section{Análise dos dados}

Foram encontrados 126 artigos relacionados à Educação Física na Educação Infantil, sendo 61 artigos nos periódicos analisados e 65 artigos nas bases de dados. Foram desconsiderados neste último os artigos idênticos aos encontrados e selecionados nos periódicos. Foi realizada a análise dos objetivos e abordagens metodológicas, com a finalidade de identificar temas e definir o seu enquadramento. A partir desse processo de análise, foram selecionados doze artigos publicados em seis periódicos específicos da Educação Física e dois artigos em periódicos da educação (Quadro 1). 


\section{QUADRO 1. ARTIGOS UTILIZADOS PARA A ANÁLISE DOS DADOS}

\begin{tabular}{|c|c|c|c|c|c|}
\hline Artigo & Autores & Ano & Métodos & Periódicos & $\begin{array}{l}\text { Web } \\
\text { Qualis }\end{array}$ \\
\hline $\begin{array}{l}\text { Considerações } \\
\text { sobre a presença } \\
\text { do esporte na } \\
\text { Educação Física } \\
\text { infantil: reflexões } \\
\text { e experiências }\end{array}$ & $\begin{array}{c}\text { Ana Cristina } \\
\text { Richter, Michelle } \\
\text { Carreirão } \\
\text { Gonçalvez; } \\
\text { Alexandre } \\
\text { Fernades Vaz } \\
\end{array}$ & 2011 & $\begin{array}{l}\text { Relato de } \\
\text { Experiência }\end{array}$ & $\begin{array}{l}\text { Educar em } \\
\text { Revista }\end{array}$ & B2 \\
\hline $\begin{array}{c}\text { Atividades } \\
\text { motoras } \\
\text { cotidianas e suas } \\
\text { influências no } \\
\text { desenvolvimento } \\
\text { de pré-escolares }\end{array}$ & $\begin{array}{l}\text { Maria Catarina } \\
\text { Meirelles Faria e } \\
\text { Colaboradores. }\end{array}$ & 2010 & $\begin{array}{l}\text { Pesquisa- } \\
\text { Ação }\end{array}$ & $\begin{array}{l}\text { Movimento. } \\
\text { Revista de } \\
\text { Educação } \\
\text { Física da } \\
\text { UFRGS }\end{array}$ & $\mathrm{A} 2$ \\
\hline $\begin{array}{c}\text { Relações } \\
\text { sociais no } \\
\text { desenvolvimento } \\
\text { da imaginação por } \\
\text { meio de jogos }\end{array}$ & $\begin{array}{l}\text { João Batista } \\
\text { Freire; Geisa } \\
\text { Mara Laguna } \\
\text { Santana. }\end{array}$ & 2007 & $\begin{array}{l}\text { Pesquisa- } \\
\text { Ação }\end{array}$ & \multirow{2}{*}{$\begin{array}{l}\text { Motriz. Revista } \\
\text { de Educação } \\
\text { Física }\end{array}$} & \multirow[t]{2}{*}{ B1 } \\
\hline $\begin{array}{c}\text { A ação pedagógica } \\
\text { sob a perspectiva } \\
\text { de Henri Wallon }\end{array}$ & $\begin{array}{c}\text { Elaine Gomes } \\
\text { dos Santos, José } \\
\text { Milton de Lima } \\
\end{array}$ & 2009 & $\begin{array}{l}\text { Pesquisa- } \\
\text { Ação }\end{array}$ & & \\
\hline $\begin{array}{c}\text { Narrando } \\
\text { Experiências com } \\
\text { a Educação Física } \\
\text { na Educação } \\
\text { Infantil }\end{array}$ & Eliane Ayoub & 2005 & $\begin{array}{l}\text { Relato de } \\
\text { Experiência }\end{array}$ & \multirow{2}{*}{$\begin{array}{l}\text { Revista } \\
\text { Brasileira de } \\
\text { Ciências do } \\
\text { Esporte }\end{array}$} & \multirow{2}{*}{ B1 } \\
\hline $\begin{array}{l}\text { Educação Física } \\
\text { na Educação } \\
\text { Infantil: produção } \\
\text { de saberes no } \\
\text { cotidiano escolar }\end{array}$ & $\begin{array}{l}\text { André da Silva } \\
\text { Mello, et al }\end{array}$ & 2014 & $\begin{array}{l}\text { Estudo com } \\
\text { o Cotidiano }\end{array}$ & & \\
\hline $\begin{array}{c}\text { Como brincar } \\
\text { pode auxiliar no } \\
\text { desenvolvimento } \\
\text { de } \\
\text { Crianças pré- } \\
\text { escolares }\end{array}$ & $\begin{array}{l}\text { Rute Estanislava } \\
\text { Tolocka, et al. }\end{array}$ & 2009 & $\begin{array}{l}\text { Pesquisa- } \\
\text { Ação }\end{array}$ & Revista Licere & B1 \\
\hline
\end{tabular}




\begin{tabular}{|c|c|c|c|c|c|}
\hline $\begin{array}{c}\text { Análise das } \\
\text { estratégias } \\
\text { metodológicas das } \\
\text { aulas de dança } \\
\text { improvisação na } \\
\text { Educação Física } \\
\text { infantil }\end{array}$ & $\begin{array}{c}\text { Queila da Silva; } \\
\text { Marcelo Victor } \\
\text { Rosa }\end{array}$ & 2008 & \multirow[t]{2}{*}{$\begin{array}{l}\text { Pesquisa- } \\
\text { Ação }\end{array}$} & \multirow{3}{*}{$\begin{array}{l}\text { Motrivivência } \\
\text { Revista de } \\
\text { Educação } \\
\text { Física, Esporte } \\
\text { e Lazer }\end{array}$} & \multirow{3}{*}{ B2 } \\
\hline $\begin{array}{l}\text { As crianças } \\
\text { como autoras da } \\
\text { significação da } \\
\text { Educação Física }\end{array}$ & $\begin{array}{c}\text { Rubens } \\
\text { Machado, Bruno } \\
\text { Fagundes, } \\
\text { Fabiano Weber } \\
\text { da Silva }\end{array}$ & 2011 & & & \\
\hline $\begin{array}{c}\text { O lugar da } \\
\text { Educação Física na } \\
\text { Educação Infantil, } \\
\text { existe? }\end{array}$ & $\begin{array}{l}\text { Vilma Pinho, } \\
\text { José Tarcísio } \\
\text { Grunennvaldt, } \\
\text { Kátia Garcia } \\
\text { Gelamo }\end{array}$ & 2016 & $\begin{array}{l}\text { Estudo de } \\
\text { Caso }\end{array}$ & & \\
\hline $\begin{array}{c}\text { Os projetos } \\
\text { de ensino e a } \\
\text { Educação Física na } \\
\text { Educação Infantil }\end{array}$ & $\begin{array}{c}\text { Amanda } \\
\text { Fonseca Soares. }\end{array}$ & 2002 & $\begin{array}{l}\text { Pesquisa- } \\
\text { Ação }\end{array}$ & \multirow{3}{*}{$\begin{array}{l}\text { Revista Pensar } \\
\text { Elaborado } \\
\text { a partir dos } \\
\text { questionários a } \\
\text { Prática }\end{array}$} & \multirow{3}{*}{ B2 } \\
\hline $\begin{array}{c}\text { O cotidiano da } \\
\text { Educação Infantil } \\
\text { e a presença da } \\
\text { Educação Física } \\
\text { na poética de ser } \\
\text { criança }\end{array}$ & $\begin{array}{l}\text { Victor José } \\
\text { Machado de } \\
\text { Oliveira, David } \\
\text { Gomes Martins, } \\
\text { Nilton Poletto } \\
\text { Pimentel }\end{array}$ & 2013 & $\begin{array}{l}\text { Relato de } \\
\text { Experiência }\end{array}$ & & \\
\hline $\begin{array}{l}\text { Saberes e fazeres } \\
\text { praticados nos } \\
\text { cotidianos da } \\
\text { Educação Física na } \\
\text { Educação Infantil }\end{array}$ & $\begin{array}{c}\text { Kezia Rodrigues } \\
\text { Nunes, Amarílio } \\
\text { Ferreira Neto }\end{array}$ & 2011 & $\begin{array}{c}\text { Pesquisa de } \\
\text { Campo }\end{array}$ & & \\
\hline $\begin{array}{l}\text { Sobre os modos } \\
\text { de praticar } \\
\text { Educação Física } \\
\text { na Educação na } \\
\text { Educação Infantil }\end{array}$ & $\begin{array}{c}\text { Ana Cristina } \\
\text { Richter, } \\
\text { Alexandre } \\
\text { Fernandez Vaz }\end{array}$ & 2012 & $\begin{array}{c}\text { Pesquisa de } \\
\text { Campo }\end{array}$ & $\begin{array}{c}\text { Revista } \\
\text { Estudos } \\
\text { Pedagógicos, } \\
\text { Monográficos } \\
\text { Extraordinários }\end{array}$ & $\mathrm{B} 1 *$ \\
\hline
\end{tabular}

Fonte: Elaborado a partir dos artigos selecionados para a análise dos dados (*) Avaliação Qualis para a área da Educação 
A análise dos dados norteou-se a partir da análise do conteúdo proposto por Bardin (1977), que transcorreu por três etapas. A primeira permeia a pré-análise, caracterizada, neste estudo, pela leitura flutuante dos quatorze artigos selecionados com o objetivo de sistematizar as ideias iniciais. A segunda refere-se à categorização dos dados, delineado pela leitura aprofundada dos artigos, de modo que os dados encontrados fossem categorizados em unidades significativas, a fim de identificar os aspectos que apontassem para a qualidade da prática pedagógica no que concerne as aulas de Educação Física na Educação Infantil. Considerando o que orientam os documentos normativos (BRASIL, 1998; BRASIL, 2010; BRASIL, 2017) em relação ao protagonismo das crianças nas práticas pedagógicas e o referencial produzido acerca dos objetivos da Educação Física na Educação Infantil, o estudo permeia seis categorias, sendo: interdisciplinaridade, autonomia, relações interpessoais, diálogo, motivação e jogo simbólico. Assim, tais categorias se constituíram a partir dos conteúdos manifestos e latentes (MOZZATO; GRZYBOVSKI, 2011), buscando os sentidos e significados que emergem dos artigos primários. E, por fim, a terceira etapa, que consiste nas inferências e interpretação dos resultados.

\section{Estratégias metodológicas que corroboram com a qualidade da prática pe- dagógica}

Destacamos, enquanto indicadores da qualidade das práticas pedagógicas que envolvem os conteúdos da Educação Física na Educação Infantil, o reconhecimento da criança enquanto protagonista de sua aprendizagem, de modo que as intencionalidades educativas considerem a elas em sua totalidade, garantindo a exploração e vivência das diferentes práticas corporais nos diferentes tempos e espaços do cotidiano institucional. Com a análise, foi possível constatar que uma quantidade significativa dos artigos resultaram de projetos de pesquisa relacionados ao objeto de estudo (FREIRE; SANTANA, 2007; SILVA; ROSA, 2008; FARIA et al., 2009; SANTOS; LIMA, 2009; NUNES; FERREIRA NETO, 2011; RICHTER; VAZ, 2012; MELLO et al., 2014; PINHO; GRUNENNVALDT; GELAMO, 2016), outros resultaram das intervenções pedagógicas do estágio supervisionado (AYOUB, 2005; TOLOCKA et al., 2009; RICHTER; GONÇALVES; VAZ, 2011; MACHADO; FAGUNDES; SILVA, 2011; OLIVEIRA; MARTINS; PIMENTEL, 2013), e um estudo foi encomendado pelo Ministério da Educação (SOARES, 2002).

Com a análise, percebe-se que são limitados os estudos que envolvem as práticas pedagógicas com os conteúdos da Educação Física na Educação 
Infantil. Identifica-se um aumento, a passos lentos, das discussões acerca da temática na última década. Nas análises, evidencia-se que os estudos que resultaram de intervenções pedagógicas do estágio supervisionado estabelecem a aproximação entre a teoria e a prática, a discussão e reflexão sobre os desafios da legitimação da Educação Física no contexto infantil, e incidem com os resultados encontrados nos demais artigos analisados. Contudo, não podem ser comparadas às intervenções, ainda que restritas, realizadas com os professores que atuam neste contexto, pois tais intervenções visam atender ao processo de formação profissional, e nem sempre para atender os objetivos de aprendizagem da Educação Infantil. Havendo, assim, a necessidade de o professor/pesquisador desenvolver pesquisas que possam intervir e refletir positivamente em sua própria prática, contribuindo para a legitimação da Educação Física neste contexto (MACHADO; FAGUNDES; SILVA, 2011; SOARES, 2002). Neste sentido, Pinho, Grunennvaldt e Gelano (2016) e Freire e Santana (2007) afirmam haver um lugar para a Educação Física na Educação Infantil, desde que o/a professor/a sistematize a aula e trabalhe com a tematização dos conteúdos.

No que se refere aos conteúdos desenvolvidos durante as aulas de Educação Física, foram identificados os conhecimento sobre o corpo (AYOUB, 2005; SANTOS; LIMA, 2009), os jogos e brincadeiras (AYOUB, 2005; SANTOS; LIMA, 2009; FREIRE, SANTANA, 2007; FARIA et al., 2009; NUNES; FERREIRA NETO, 2011; RICHTER; VAZ, 2012; OLIVEIRA; MARTINS; PIMENTEL, 2013; MELLO et al., 2014; PINHO; GRUNENNVALDT; GELAMO, 2016), as danças e cantigas de roda (SILVA; ROSA, 2008; SANTOS; LIMA, 2009), esportes (RICHTER; GONÇALVES; VAZ, 2011; PINHO; GRUNENNVALDT; GELAMO, 2016), ginásticas e lutas (PINHO; GRUNENNVALDT; GELAMO, 2016). Com os dados, é possível inferir que os jogos e brincadeiras são os conteúdos mais privilegiados nas práticas pedagógicas. Considerando a importância para o desenvolvimento da criança nos estudos, os jogos e brincadeiras foram contemplados enquanto conteúdos dos projetos didáticos (AYOUB, 2005; FREIRE; SANTANA, 2007), como também organizados e sistematizados durante o planejamento. Dentre os objetivos destacaram-se a socialização, o desenvolvimento da imaginação (FREIRE; SANTANA, 2007), de habilidades motoras e manipulativas, a criação de enredos e cenários de reconhecimento e desenvolvimento de diferentes papeis sociais (MELLO et al., 2014), realização de atividades fisicamente ativas (FARIA et al., 2009) e a apropriação de cultura (PINHO; GRUNENNVALDT; GELAMO, 2016).

Quanto a prática pedagógica no ensino da Educação Física na Educação Infantil, as estratégias metodológicas identificadas nos estudos primários 
distribuem-se em seis categorias. A primeira refere-se à interdisciplinaridade, que tem como objetivo a realização de práticas pedagógicas que favoreçam a construção do conhecimento em sua totalidade. Nos estudos de Soares (2002), Ayoub (2005), Freire e Santana (2007), Richter, Gonçalves e Vaz (2011), Nunes e Ferreira Neto (2011), Richter e Vaz (2012), foram identificados os projetos didáticos pedagógicos como um dos principais meios para atender aos objetivos de aprendizagem na Educação Infantil. Conforme os autores, nos projetos, as práticas pedagógicas surgem a partir da curiosidade da criança de aprender sobre determinados assuntos e temas. No entanto, Soares (2002) e Oliveira, Martins e Pimentel (2013) salientam que os projetos devem resultar de ações pedagógicas organizadas em busca da solução de um problema, e não apenas caracterizar-se como uma sequência de passos a serem seguidos.

O trabalho pedagógico a partir de projetos possibilita a aproximação e interação com outros profissionais da instituição, evidenciando um melhor desempenho das atividades propostas (AYOUB, 2005). Da mesma maneira, Soares (2002) enfatiza para a necessidade de atrelar as aulas de Educação Física aos projetos pedagógicos, pressupondo um trabalho de organização coletiva e integrada, de que participam os demais professores, gestão escolar, pais e comunidade, valorizando a compreensão das crianças e ajudando-os a construir o conhecimento de forma global. Freire e Santana (2007) identificaram que, na instituição analisada, o trabalho pedagógico era organizado por projetos que visavam ampliar as diferentes linguagens de expressão, o que facilitou a organização do planejamento do/a professor/a, pois as brincadeiras e atividades propostas durante as aulas passaram a ser direcionadas a partir dos temas geradores. Richter e Vaz (2012, p. 319) asseguram que a utilização de projetos "favorece a interação de crianças de diferentes faixas etárias; a superação de uma demarcação rígida de horários", além de possibilitar a exploração de diferentes espaços institucionais e não institucionais.

Outro aspecto importante da prática pedagógica refere-se ao professor/a criar situações em que o aluno "se torne participativo e integrante do processo de ensino aprendizagem", de modo que consiga significar em seu cotidiano os movimentos corporais realizados durante as aulas (SURDI; MELO; KUNZ, 2015, p. 467). Logo, a segunda categoria de análise diz respeito à autonomia. Isso significa que não cabe ao professor/a ensinar movimentos estereotipados, prontos e acabados, mas possibilitar situações em que as crianças criem enredos, construam e modifiquem os cenários das brincadeiras, podendo desenvolver a capacidade de solucionar diferentes conflitos e problemáticas de seu dia-a-dia (TOLOCKA, et al., 2009; FARIA, et al., 2009). Santos e 
Lima (2009) enfatizam que o professor deve respeitar o tempo e vontade do aluno, pois há a necessidade de a criança sentir-se a vontade para executar as atividades, e não por estarem sendo impostas pelo professor/a. Práticas pedagógicas com estes aspectos foram identificadas nos resultados de Freire e Santana (2007, p. 255), nas quais "as próprias crianças se revezavam nos papéis de lobo, meninos, irmãs e mamãe [...] começam a se organizar para construir o cenário da brincadeira [...] se articulam, trocam materiais, escolhem o local para as construções, decidem quem é quem na brincadeira".

Do mesmo modo, os estudos de Richter, Gonçalves e Vaz (2011), Machado, Fagundes e Silva (2011), Oliveira, Martins e Pimentel (2013), Mello et al. (2014) e Pinho, Grunennvaldt e Gelamo (2016) ressaltam a necessidade de permitir que as crianças sejam protagonistas de seu processo de aprendizagem. Isso significa, permitir durante a prática pedagógica que a criança explore novos espaços, crie e reformule as brincadeiras, participe de situações de escolha, manipule diferentes brinquedos e materiais (RICHTER; VAZ, 2012), ou seja, extrapole os limites impostos pelos adultos. Assim, a prática pedagógica deverá possibilitar as crianças liberdade para decidir, criar e tomar iniciativas.

A terceira categoria concerne às relações interpessoais, pois exercem papel fundamental no desenvolvimento da criança. Santos e Lima (2009), ao realizarem suas intervenções pautadas na Teoria de Wallon, ressaltam que a aprendizagem da criança ocorre a partir das relações com as pessoas e o ambiente. Oliveira, Martins e Pimentel (2013) enfatizam a necessidade de práticas pedagógicas que proporcionem momentos de interação em espaços coletivos, destacando o brincar como uma das principais estratégias. Conforme Mello et al. (2014, p. 477), ao brincar a criança organiza suas ações, "institui coletivamente uma ordem social que rege as relações entre pares". Nos estudos destacaram-se, atividades de pegador, jogos de construção e jogos com representações de papéis sociais como possibilidades de interações interpessoais.

Richter e Vaz (2012) ressaltam a importância de as instituições de Educação Infantil estabelecerem, em suas rotinas, momentos de interação com crianças de outras salas. Freire e Santana (2007), Faria et al. (2009) e Tolocka et al. (2009) afirmam ser o/a professor/a um dos principais responsáveis em propiciar momentos em que as crianças possam interagir com seus pares. Freire e Santana (2007, p. 256) apresentam, no relato do diário de campo a execução de um jogo de construção que "as crianças interagiam, conversavam sobre o que estavam fazendo, formavam duplas, uma buscava as tampinhas necessárias e a outra construía o que haviam combinado", deixando evidente a criação de parcerias nas relações pessoais. Nas intervenções de Ayoub (2005) a estimula- 
ção das relações interpessoais predominou nas dinâmicas de interação grupal, onde as crianças deveriam experimentar ou imitar os movimentos sugeridos pelos colegas. Faria et al. (2009) propôs em seu estudo a realização do evento 'minicirco', no qual participaram crianças de outras faixas etárias como também de outras escolas, proporcionando assim momentos de interações coletivas.

O diálogo é apontado como uma estrutura primordial para as intervenções na Educação Infantil, configurando, assim, a quarta categoria de análise. Nos artigos, destaca-se a importância do diálogo como estratégia de motivação e solução de problemas relacionados às emoções, conflitos e perturbações (SANTOS; LIMA, 2009; RICHTER; VAZ, 2012), para a introdução de novas temáticas, construção de novas brincadeiras e novos conceitos sobre as práticas corporais (PINHO; GRUNENNVALDT; GELAMO, 2016), como também momento oportuno para realização de um feedback das atividades realizadas e expressão dos sentimentos (MACHADO; FAGUNDES; SILVA, 2011). Nos estudos de Ayoub (2005), Freire e Santana (2007), Richter, Gonçalves e Vaz (2011) e Oliveira, Martins e Pimentel (2013), a prática da roda de conversa surge como principal estratégia de diálogo e estreitamento das relações entre professor-aluno e aluno-aluno. Assim, conforme Ayoub (2005), as rodas de conversa possibilitam momentos de discussão acerca dos temas, apresentação das atividades, retomada de assuntos já vistos e momento em que as crianças podem expressar suas ideias, podendo ser desenvolvidas em qualquer momento em que requer diálogo sobre algum assunto.

A partir da análise do conteúdo, foi possível constatar que o/a professor/a, durante suas práticas pedagógicas deve usufruir de variados meios para motivar os alunos, de modo que estes permaneçam o maior tempo possível engajado nas atividades propostas. Esse aspecto evidencia a quinta categoria da investigação. Freire e Santana (2007) salientam que, apesar da criança da Educação Infantil ser pequena, seu tempo de concentração varia conforme o que lhe é proposto. Assim, atividades que despertam maior interesse da criança, consequentemente, exigirão um tempo maior para a sua realização (MACHADO; FAGUNDES; SILVA, 2011).

Despertar o interesse da criança exige práticas desafiadoras. Para Freitas e Stigger (2015, p. 80), o desafio é o principal elemento que torna uma brincadeira atrativa, porém “o 'saber fazer' é tão importante quanto o desafio lançado". Assim, os desafios devem ser condizentes com as características do desenvolvimento, bem como atender os anseios e curiosidades da criança. $\mathrm{Na}$ análise, identificamos esta estratégia no estudo de Oliveira, Martins e Pimentel (2013), que enfatizam a necessidade de transformar as brincadeiras em 
desafios. Nas intervenções de Richter, Gonçalves e Vaz (2011), as crianças são desafiadas a devolver, ao final da corrida de revezamento, o 'baldinho' com água que, no início da atividade, estava cheio. Nas intervenções de Santos e Lima (2009), situações de desafio aparecem no momento em que a professora duvida que alguma criança conseguiria fazer a atividade que, aparentemente, seria muito difícil, ou, se durante a realização do jogo simbólico, teriam coragem de entrar na caverna em que o lobo estava escondido. Tais estratégias estimularam a atenção e euforia dos alunos para a realização das atividades propostas.

Conforme a análise, utilizar diferentes materiais também é uma estratégia importante para motivar as crianças, pois chamam a atenção, despertam a curiosidade e estimulam habilidades manipulativas. Tolocka et al. (2009) destacam que além do próprio corpo, podem ser usados arcos, bolas, bexigas, jornal e cordas, durante a realização das brincadeiras. No estudo de Freire e Santana (2007), os materiais eram compostos por caixas de diversos tamanhos, bolas, latas, cordas, tecidos, tampinhas de garrafas pets e garrafas pets, balão e brinquedos como: bonecas, loucinhas, adereços e fantasias. Em suas intervenções, Faria et al. (2009) disponibilizaram matérias de fácil manipulação, sendo lenços coloridos, bolas coloridas, tubos de papelão, petecas e pneus. Em suas propostas, Richter, Gonçalves e Vaz (2011) utilizaram raquetes de tênis, livros, lápis, revistas, canetas, boia, remos, fitas, colchonete, tacos, dardos, pesos, discos, tabuleiro de xadrez, sapatilhas de balé, berimbau, pequenas traves de futebol, cordas, pipas, entre muitos outros como os galhos que as crianças encontraram na praia. E, no estudo de Santos e Lima (2009), foram utilizados um estetoscópio e um urso de pelúcia.

Apesar das múltiplas sugestões de materiais, é necessário que o/a professor/a privilegie situações em que os alunos possam construir seus próprios brinquedos, experimentando elementos culturais de diferentes naturezas e construindo suas significações. Soares (2002) e Ayoub (2005) propuseram a construção de brinquedos populares, sendo o papagaio, carinho de rolimã, peteca e barangandã. Em suas intervenções, Santos e Lima (2009) propuseram a construção do peixinho de origami, e Richter, Gonçalves e Vaz (2011) construíram discos com bandejas de papelão. Além da construção dos brinquedos, Freire e Santana (2007) e Oliveira, Martins e Pimentel (2013) ressaltam a importância da realização dos jogos de construção, evidenciando à criança o papel de produtora da sua própria cultura lúdica.

Estudos relacionados ao jogo e desenvolvimento humano apontam as situações imaginárias e imitativas como importante aspecto para a estimulação 
da aprendizagem das crianças. O jogo simbólico delineará a sexta categoria do estudo. Conforme Vigotski (1991), a situação imaginária é um meio para desenvolver o pensamento abstrato, como também para a manifestação de propriedades autorreguladoras. Para Alves (1987), ao utilizar a imaginação, a criança alcança uma liberdade que, muitas vezes, é inexistente e, Chateau (1987) afirma que, com a utilização do imaginário, a criança estrutura esquemas práticos necessários à vida adulta. Deste modo, é necessário que, durante as práticas pedagógicas, o/a professor/a usufrua dos jogos do mundo imaginário e do faz de conta.

Para esta categoria, são elencados os jogos que utilizam a ficção, imitação, representação e imaginação. Nas intervenções analisadas, observa-se que o jogo simbólico é desenvolvido como conteúdo das aulas, mas também como estratégia metodológica para o ensino de outros conteúdos. Ayoub (2005) propôs atividades onde os alunos representavam uma história e exerciam o papel de soldados, tendo a importante missão de salvar o 'Mico Leão Dourado'. No estudo de Freire e Santana (2007), a professora propôs que os alunos fechassem os olhos e tentassem imaginar algo para depois representar com as tampinhas, sempre os indagando sobre o que estavam vendo, além da representação de papéis sociais, utilizando os variados materiais disponibilizados. A representação de papéis sociais também ficou evidente nos estudos de Tolocka et al. (2009) e Faria et al. (2009), como perseguidor, atleta, dançarino, motorista, herói, escultor, equilibrista, jogador de futebol, cavaleiro, pintor, escultor e lutador, permitindo à criança explorar e compreender o contexto em que está inserida.

As intervenções realizadas por Machado, Fagundes e Silva (2011) tiveram as atividades de mímicas, a realização de um caça ao tesouro 'O Segredo da Educação Física', em que as crianças adentraram no universo imaginário de forma curiosa e autônoma ao procurarem as pistas do tesouro. Santos e Lima (2009) exercitaram a função simbólica das crianças, propondo a utilização da ficção, ao imaginarem que estavam na floresta à procura do lobo, no mar a bordo de um navio e a criação de um ambiente com os personagens marinheiro e tubarão para brincarem com o peixinho de origami. Mello et al. (2014, p. 479) usufruíram das atividades de imitação, faz de conta e "brincadeiras historiadas" com construção de fantoches.

Apesar das seis categorias elencadas neste estudo, constamos, também, que houve pouca discussão no que tange ao movimento na Educação Infantil. Os estudos ressaltaram a importância do movimentar-se para desenvolvimento da criança, no entanto foram escassas as intervenções que propuseram 
atividades fisicamente ativas, como o correr, saltar, equilibrar, entre outras. Logo, não estamos enfatizando o desenvolvimento de aulas estruturadas em uma perspectiva unicamente desenvolvimentista, mas na necessidade de as crianças vivenciarem uma diversidade de movimentos e que tenham liberdade para explorarem e usufruírem dos variados espaços disponíveis na instituição (TOLOCKA et al., 2009; FARIA et al., 2009).

\section{Considerações finais}

Ao analisar os estudos selecionados, identifica-se que as práticas pedagógicas superam a perspectiva de que as aulas nestes espaços, são para descontrair ou relaxar as crianças, pois verifica-se que as atividades são sistematizadas e tematizam diferentes conteúdos (conhecimentos sobre o corpo, jogos, brincadeiras cantadas, danças, ginásticas) das práticas corporais. Enquanto estratégias metodológicas para a qualidade da prática pedagógica acerca dos conteúdos da Educação Física na Educação Infantil, destacam-se as seis categorias utilizadas pelos professores.

Em síntese, destaca-se o trabalho interdisciplinar por meio de projetos didáticos pedagógicos, procurando envolver as crianças e a comunidade escolar. A estimulação da autonomia da criança, por meio da participação em situação de escolhas, na manipulação e construção de diferentes materiais, na exploração dos diferentes espaços, na modificação e construção dos cenários das brincadeiras. A estimulação das relações interpessoais com os pares de diferentes faixas etárias e adultos. A utilização do diálogo, por meio de rodas de conversa para a solução de problemáticas relacionadas as emoções e conflitos, como também para a realização de feedbacks e introdução de novas temáticas. A motivação, utilizando-se de diferentes materiais, da curiosidade da criança e de desafios condizentes com as suas capacidades. E a estimulação de situações imaginárias, utilizando-se dos jogos simbólicos. Tais estratégias extrapolam a mera utilização de movimentos estereotipados e proporcionam à criança a exploração e vivência de variadas práticas corporais nos diferentes tempos e espaços do contexto institucional, estimulando não apenas os seus movimentos, mas também a criatividade, imaginação e autonomia da criança.

Diante disso, enfatiza-se necessidade de os/as professores/as desenvolverem investigações no contexto que estão inseridos, a fim de contribuírem para a solução de problemáticas que permeiam os conteúdos da Educação Física na Educação Infantil. Por fim, é oportuno enfatizar que, devido ao recorte metodológico da revisão sistemática, o estudo retrata apenas uma parcela das 
publicações cientificas neste campo de estudo. Tendo em vista estes aspectos, espera-se que este estudo possa contribuir com as discussões e reflexões acerca da legitimação da Educação Física nesta etapa de ensino.

\section{Referências}

ALVES, Rubem. A Intenção lúdica da imaginação. ALVES, Rubem. A gestação do futuro. Campinas: Papirus,1987. p. 95-107.

ANDRADE FILHO, Nelson Figueiredo de. Observação compreensivo-crítica das experiências de movimento corporal das crianças na educação infantil. Movimento, Porto Alegre, v. 19, n. 01, p. 55-71, 2013. Disponível em: < http://seer. ufrgs.br/index.php/Movimento/article/view/26491/24401 >. Acesso em: 02 de fev. de 2017.

AYOUB, Eliane. Reflexões sobre a Educação Física na educação infantil. Revista. Paulista de Educação Física, São Paulo, supl.4, p.53-60, 2001. Disponível em: < http://files.pensando-em-educacao.webnode.com/200000096-31e7432e1d/v15\%20supl4\%20artigo6.pdf >. Acesso em: 10 de fev. de 2017.

AYOUB, Eliane. Narrando experiências com a Educação Física na educação infantil. Revista Brasileira de Ciências do Esporte, Campinas, v. 26, n. 3, p. 143-158, 2005. Disponível em: < http://www.revista.cbce.org.br/index.php/ RBCE/article/view/165 >. Acesso em 12 de fev. de 2017.

BARDIN, Laurence. Análise de Conteúdo. Portugal: Edições 70, 1977.

BASEI, Andréia Paula. A Educação Física na Educação Infantil: a importância do movimentar-se e suas contribuições no desenvolvimento da criança. Revista Iberoamericana de Educación, [S. 1.], v. 47, n. 3, p. 1-12, 2008. Disponível em: < http://rieoei.org/deloslectores/2563Basei.pdf >. Acesso em 12 de fev. de 2017.

BRASIL. Ministério da Educação e do Desporto. Secretaria de Educação Fundamental. Referencial Curricular Nacional para a Educação Infantil. Brasília: $\mathrm{MEC} / \mathrm{SEF}$, v. 3, 1998.

BRASIL. Ministério da Educação. Secretaria de Educação Básica. Diretrizes Curriculares Nacionais para a Educação Infantil. Brasília: MEC/ SEB, 2010.

BRASIL. Lei no 12.796, de 4 de abril de 2013. Altera a Lei no 9.394, de 20 de dezembro de 1996. Disponível em < http://www.planalto.gov.br/ccivil_03/ Ato2011-2014/2013/Lei/L12796.htm\#art1 >. Acesso em: 20 de jun. de 2017. 
BRASIL. Ministério da Educação. Base Nacional Comum Curricular. Versão final, 2017 Disponível em < http://basenacionalcomum.mec.gov.br/images/ pdf/3_BNCC-Final_Infantil.pdf > acesso em 31 de mai. de 2017.

CAPARROZ, Francisco Eduardo; BRACHT, Valter. O tempo e o lugar de uma didática da Educação Física. Revista Brasileira de Ciências do Esporte, Campinas, v. 28, n. 2, p. 21-37, 2007. Disponível em: < http://revista.cbce.org.br/ index.php/RBCE/article/view/53 >. Acesso em: 10 de jun. de 2017.

CAVALARO, Adriana Gentilin; MULLER, Verônica Regina. Educação Física na Educação Física na Educação Infantil: uma realidade almejada. Educar em Revista, Curitiba, n. 34, p. 241-250, 2009. Disponível em: < http://revistas.ufpr. br/educar/article/view/8184 >. Acesso em: 05 de fev. de 2017.

CHATEAU, Jean. Por que a criança brinca?. In: CHATEAU, Jean. O Jogo e a Criança. São Paulo: Summus, 1987, p.13-33.

FALKENBACH, Atos Prinz; DREXLER, Greice; WERLE, Verônica. Investigando a Ação Pedagógica da Educação Física na Educação Infantil. Movimento, Porto Alegre, v.12, n. 01, p. 81-103, 2006. Disponível em: < http://seer.ufrgs.br/ index.php/Movimento/article/view/2892/1528 >. Acesso em: 29 de jan. de 2017.

FARIA, Maria Catarina Meirelles et al. Atividades motoras cotidianas e suas influências no desenvolvimento de pré-escolares. Movimento, Porto Alegre, v. 16, n. 1, p. 113-130, 2009. Disponível em: < http://www.seer.ufrgs.br/index. php/Movimento/article/view/4991/7520 >. Acesso em: 25 mar. 2017.

FAZENDA, Ivani Catarina Arantes. Interdisciplinaridade-transdisciplinaridade: visões culturais e epistemológicas. In: FAZENDA, Ivani Catarina Arantes. (Org.) O que é interdisciplinaridade?. São Paulo: Cortez, p. 17-28, 2008.

FERRAZ, Osvaldo Luiz; MACEDO, Lino de. Reflexões de professores sobre a educação física na educação infantil incluindo o Referencial Curricular Nacional. Revista Paulista de Educação Física, São Paulo, 15(1):83-102, jan./ jun. 2001. Disponível em: < http://citrus.uspnet.usp.br/eef/uploads/arquivo/ v15\%20n1\%20artigo7.pdf >. Acesso em: 30 de jan. de 2018.

FREIRE, João Batista; SANTANA, Geisa Mara Laguna. Relações sociais no desenvolvimento da imaginação por meio de jogos. Motriz, Rio Claro, v.13 n.4 p.249-258, 2007. Disponível em: < http://www.periodicos.rc.biblioteca. unesp.br/index.php/motriz/article/view/877/1172>. Acesso em: 09 de mar. de 2017.

FREITAS, Maitê Venuto de; STIGGER, Marco Paulo. As brincadeiras nas aulas

Rev. Fac. Educ. (Univ. do Estado de Mato Grosso), Vol. 33, Ano 18, № 1, p. 95-118, jan./jul., 2020 (Epub Ahead of Print 15 set., 2019 ). 
de Educação Física e seus significados para as crianças. Motrivivência, Florianópolis, v. 27, n. 45, p. 74-83, 2015. Disponível em: < https://periodicos.ufsc. $\mathrm{br}$ /index.php/motrivivencia/article/view/2175-8042.2015v27n45p74/30196 >. Acesso em: 31 de fev. de 2017.

GALVÃO, Izabel. Henri Wallon: uma concepção dialética do desenvolvimento infantil. 4 ed. Petrópolis: Vozes, 1995.

GOMES, Isabelle Sena; CAMINHA, Iraquitan de Oliveira. Guia para estudos de revisão sistemática: uma opção metodológica para as Ciências do Movimento Humano. Movimento, Porto Alegre, v. 20, n. 01, p. 395-411, 2014. Disponível em: < http://www.seer.ufrgs.br/Movimento/article/viewFile/41542/28358 >.Acesso em: 31 de jan, de 2017.

HOFFMANN, Jussara. Avaliação e Educação Infantil: um olhar sensível e reflexivo sobre a criança. Porto Alegre: Mediação, 2012.

MACHADO, Rubens; FAGUNDES, Bruno; DA SILVA, Fabiano Weber. As crianças como autoras da significação da Educação Física. Motrivivência, Florianópolis, n. 37, p. 51-68, 2011. Disponível em: < https://periodicos.ufsc.br/index. php/motrivivencia/article/view/24450 >. Acesso em: 30 de jan. de 2017.

MATURANA, Humberto R.; VERDEN-ZÖLLER, Gerda. Amar e brincar: fundamentos esquecidos do humano. São Paulo: Palas Athena, 2004.

MELLO, André da Silva et al. Educação Física na educação infantil: produção de saberes no cotidiano escolar. Revista Brasileira de Ciências do Esporte, Florianópolis, v. 36, n. 2, p. 467-484, 2014. Disponível em: < http://www.scielo. $\mathrm{br} / \mathrm{pdf} / \mathrm{rbce} / \mathrm{v} 36 \mathrm{n} 2 / 0101-3289-\mathrm{rbce}-36-02-00467 . p d f$ >. Acesso em: $02 \mathrm{de}$ fev. de 2017.

MOURA, Diego Luz; NUNES COSTA, Kamilla Ribeiro; ANTUNES, Marcelo Moreira. Educação Física e educação infantil: uma análise em seis periódicos nacionais. Pensar a Prática, Goiânia, v. 19, n. 1, 2016. Disponível em: < https:// www.revistas.ufg.br/fef/article/view/34061 >. Acesso em: 02 jun. 2017.

MOZZATO, Anelise Rebelato; GRZYBOYSKI, Denize. Análise de conteúdo como técnica de análise de dados qualitativos no campo da administração: potencial e desafios. RAC, Curitiba, v. 15, n. 4, pp. 731-747, Jul./Ago. 2011. Disponível em: < www.scielo.br/pdf/rac/v15n4/a10v15n4.pdf >. Acesso em: 10 de nov. de 2017.

NUNES, Kezia Rodrigues; FERREIRA NETO, Amarílio. Saberes e fazeres praticados nos cotidianos da Educação Física na educação infantil. Pensar a Prática, Goiânia, v. 14, n. 1, p. 1-10, 2011. Disponível em: < https://www.revistas.ufg. 
br/fef/article/download/9013/9143 >. Acesso em: 31 de jan. de 2017.

OLIVEIRA, Victor José Machado de; MARTINS, David Gomes; PIMENTEL, Nilton Poletto. O cotidiano da educação infantil e a presença da Educação Física na poética de ser criança. Pensar a Prática, Goiânia v. 16, n. 1, 2013. Disponível em: < https://www.revistas.ufg.br/fef/article/view/16188/13763 >. Acesso em: $31 \mathrm{~d}$ jan. de 2017.

PINHO, Vilma; GRUNENNVALDT, José Tarcísio; GELAMO, Kátia Garcia. O lugar da Educação Física na educação infantil, existe ?. Motrivivência, Florianópolis, v. 28, n. 48, p. 222-240, 2016. Disponível em: < http://dx.doi.org/10.5007/ 2175-8042.2016v28n48p222 >. Acesso em: 02 de fev. de 2017.

RICHTER, Ana Cristina; VAZ, Alexandre Fernandez. Sobre os modos de praticar Educação Física na Educação na Educação Infantil. Estudios Pedagógicos, Monográfico Extraordinário, Valdivia, v. 38, n. especial, p. 311-325, 2012. Disponível em: < http://www.scielo.cl/pdf/estped/v38nespecial/art17.pdf >. Acesso em: 31 de jan. de 2017.

RICHTER, Ana Cristina; GONÇALVES, Michelle Carreirão; VAZ, A. F. Considerações sobre a presença do esporte na Educação Física infantil: reflexões e experiências. Educar em Revista, Curitiba, n. 41, 2011. Disponível em: < http:// revistas.ufpr.br/educar/article/view/16507 >. Acesso em: 02 de fev. de 2017.

RICHTER, Ana Cristina; VAZ, Alexandre Fernandes. Educação Física, educação do corpo e pequena infância: interfaces e contradições na rotina de uma creche. Movimento, Porto Alegre, v. 16, n. 1, 2010. Disponível em: < http://www. redalyc.org/pdf/1153/115312527004.pdf >. Acesso: 31 de jan. de 2017.

SANTOS, Elaine Gomes dos; LIMA, José Milton de. A ação pedagógica sob a perspectiva de Henri Wallon. Motriz, Rio Claro, v.15, n.2, p.340-348, 2009. Disponível em: < http://www.periodicos.rc.biblioteca.unesp.br/index.php/ motriz/article/view/2473/2376 >. Acesso em: 17 de mar. De 2017.

SAYÃO, Deborah Thomé. Educação Física na Educação infantil: Riscos conflitos e controvérsias. Motrivivência, Florianópolis, n. 13, p. 221-236, 1999. Disponível em: < https://periodicos.ufsc.br/index.php/motrivivencia/article/ view/14408/13211 >. Acesso em 31 de jan. de 2017.

SILVA, Queila da; ROSA, Marcelo Victor. Análise de estratégias metodológicas das aulas de dança improvisação na Educação Física infantil. Motrivivência, Florianópolis, n. 31, 2008. Disponível em: < https://periodicos.ufsc.br/index. $\mathrm{php} /$ motrivivencia/article/view/2175-8042.2008n31p66/12955 >. Acesso em: 01 de fev. de 2017. 
SOARES, Amanda Fonseca. Os projetos de ensino e a Educação Física na educação infantil. Pensar a Prática, Goiânia, v. 5, p. 15-38, 2002. Disponível em: < https://www.revistas.ufg.br/fef/article/view/44 >. Acesso em: 30 de jan. de 2017.

SURDI, Aguinaldo Cesar; MELO, Jose Pereira de; KUNZ, Elenor. O brincar e o se-movimentar nas aulas de Educação Física infantil: realidades e possibilidades. Movimento, Porto Alegre, v. 22, n. 2, 459-470, 2016. Disponível em: < http://www.seer.ufrgs.br/index.php/Movimento/article/view/58076/37377 > Acesso em: 03 de fev. de 2017.

THOMAS, Jerry R.; NELSON, Jack K.; SILVERMAN, Sthepen J. Métodos de pesquisa em atividade física. 6. ed. Porto Alegre: Artmed, 2012.

TOLOCKA, Rute Estanislava, et al. Como brincar pode auxiliar no desenvolvimento de Crianças pré-escolares. Licere, Belo Horizonte, v.12, n.1, 2009. Disponível em < https://seer.ufmg.br/index.php/licere/article/viewFile/614/501 >. Acesso em: 10 de mar. de 2017.

UCHÔGA, Liane Aparecida Roveran; PRODÓCIMO, Elaine. Corpo e movimento na educação infantil. Motriz, Rio Claro, v. 14, n. 3, p. 222-232, 2008. Disponível em: < https://xa.yimg.com/kq/groups/19286654/943697690/name/ 1549-8696-1-PB.pdf >. Acesso em: 02 de fev. de 2017.

VIGOTSKY, Lev Semenovitch. O papel do brinquedo no desenvolvimento. In: VIGOTSKY, Lev Semenovitch. A formação social da mente: o desenvolvimento dos processos psicológicos superiores. São Paulo: Martins Fontes, p. 105-118, 1991.

ZABALA, Antoni. A prática educativa: como ensinar. Porto Alegre: Artmed, 1998. 